\title{
Rheumatoid cachexia revisited: a metabolic co-morbidity in rheumatoid arthritis
}

\section{Kayo Masuko*}

Graduate School of Nutritional Science, Sagami Women's University, Sagamihara-shi, Japan

\section{Edited by:}

Marc Poirot, Institut National de la Santé et de la Recherche Médicale, France

Reviewed by:

Luigi Iuliano, Sapienza University of Rome, Italy

Marilia Seelaender, University of São Paulo, Brazil

\section{${ }^{*}$ Correspondence:}

Kayo Masuko, Graduate School of

Nutritional Science, Sagami Women's University, Bunkyo 2-1-1, Minami-ku,

Sagamihara-shi 252-0383, Kanagawa, Japan

e-mail:k_msk@mac.com
Rheumatoid arthritis (RA) is a chronic inflammatory disease in which pro-inflammatory cytokines, including tumor necrosis factor (TNF)- $\alpha$, play a crucial role. The chronic inflammation, combined with reduced physical activity, leads to muscle wasting whereas fat mass would be maintained; the resulting abnormal metabolic state is described as rheumatoid cachexia. Since the loss of muscle volume would be compensated by the increased fat mass, body mass index (BMI) is reported not to reflect the nutritional status in RA patients. The implication of rheumatoid cachexia for cardiovascular risk and clinical prognosis is not clearly understood, however, adequate control of disease activity in combination with appropriate physical exercise could be the most important strategy to control rheumatoid cachexia and related metabolic problems.

Keywords: rheumatoid cachexia, cachexia, sarcopenia, inflammation, rheumatoid arthritis

\section{INTRODUCTION}

Recent advances in the management of rheumatoid arthritis (RA) have reduced the frequency of so-called "cachexia" in RA patients. In such "classic" cachexia, patients often look emaciated, under a malignant or chronic inflammatory condition with appetite loss and protein degradation. However, in RA, persistent inflammation may induce muscular wasting without thinning; the muscle loss in RA would be associated with normal or even obese appearance. The condition has been named "rheumatoid cachexia." Although its impact on morbidity and mortality has been suggested, the significance of rheumatoid cachexia is not fully understood in part because of the lack of specific symptoms.

The present article reviews the current concept of rheumatoid cachexia, including the confusion regarding its clinical definition, and highlights the potential importance of physical exercise and nutritional assessment in the therapeutic strategy against RA.

\section{DEFINITION OF CACHEXIA AND RELATED CONDITIONS CACHEXIA (IN CLASSIC MEANING)}

Cachexia is manifested by unintended severe weight loss and muscle wasting, and can be defined as "a multifactorial syndrome characterized by severe weight, fat and muscle loss, and increased protein catabolism due to underlying disease $(\mathrm{s})$ " $(1,2)$. The term "cachexia" originates from the ancient Greek for "bad condition," and often occurs in patients with advanced malignancy (cancer cachexia); chronic heart failure (cardiac cachexia); chronic renal failure; chronic obstructive pulmonary disease (COPD); acquired immunodeficiency syndrome (AIDS); and many other chronic diseases, including advanced RA.

Clinically, cachexia can be detected by assessment of body composition (i.e., measurement of muscle mass and fat mass) generally using bioimpedance analysis (BIA) or dual-energy X-ray absorptiometry (DEXA). Muscle mass can be measured as fat-free mass (FFM) by BIA, or lean body mass (LBM) by DEXA; values reflect the estimated mass of skeletal muscle and its metabolic activity.

Since cachexia is known to be a major cause of increased mortality, "early and effective interventions" are needed to prevent the development of fatal metabolic abnormalities (1). To this end, efforts have been made to develop and share a consensus on the clinical definition of cachexia, including diagnostic criteria. In 2005, the Special Interest Group (SIG) on cachexiaanorexia in chronic wasting diseases was created in the European Society for Clinical Nutrition and Metabolism (ESPEN) (2). The SIG developed a clinical definition of cachexia (Table 1), and to prevent delayed diagnosis and intervention, introduced the term "pre-cachexia." Pre-cachexia was defined as the simultaneous presence of the following four features; an underlying chronic disease; unintentional body weight (BW) loss ( $\leq 5 \%)$ [cf: $(\geq)$ in cachexia] during the last 6 months; chronic or recurrent systemic inflammation; and anorexia or symptoms of appetite loss (2).

Both cachexia and pre-cachexia are frequently associated with inflammation; an imbalance between pro-inflammatory (TNF- $\alpha$, Interleukin (IL)-6, and IL-1) and anti-inflammatory (e.g., IL-4, IL12 , IL-15) cytokines is considered to contribute to the pathogenesis $(2,3)$ (Table 1).

\section{SARCOPENIA}

Sarcopenia is defined as "a syndrome characterized by progressive and generalized loss of skeletal muscle mass and strength with a risk of adverse outcomes such as physical disability, poor quality of life, and death" (3). Primary sarcopenia is usually due to aging, while secondary sarcopenia occurs due to chronic illness, 
Table 1 | Clinical criteria for cachexia, rheumatoid cachexia, and sarcopenia.

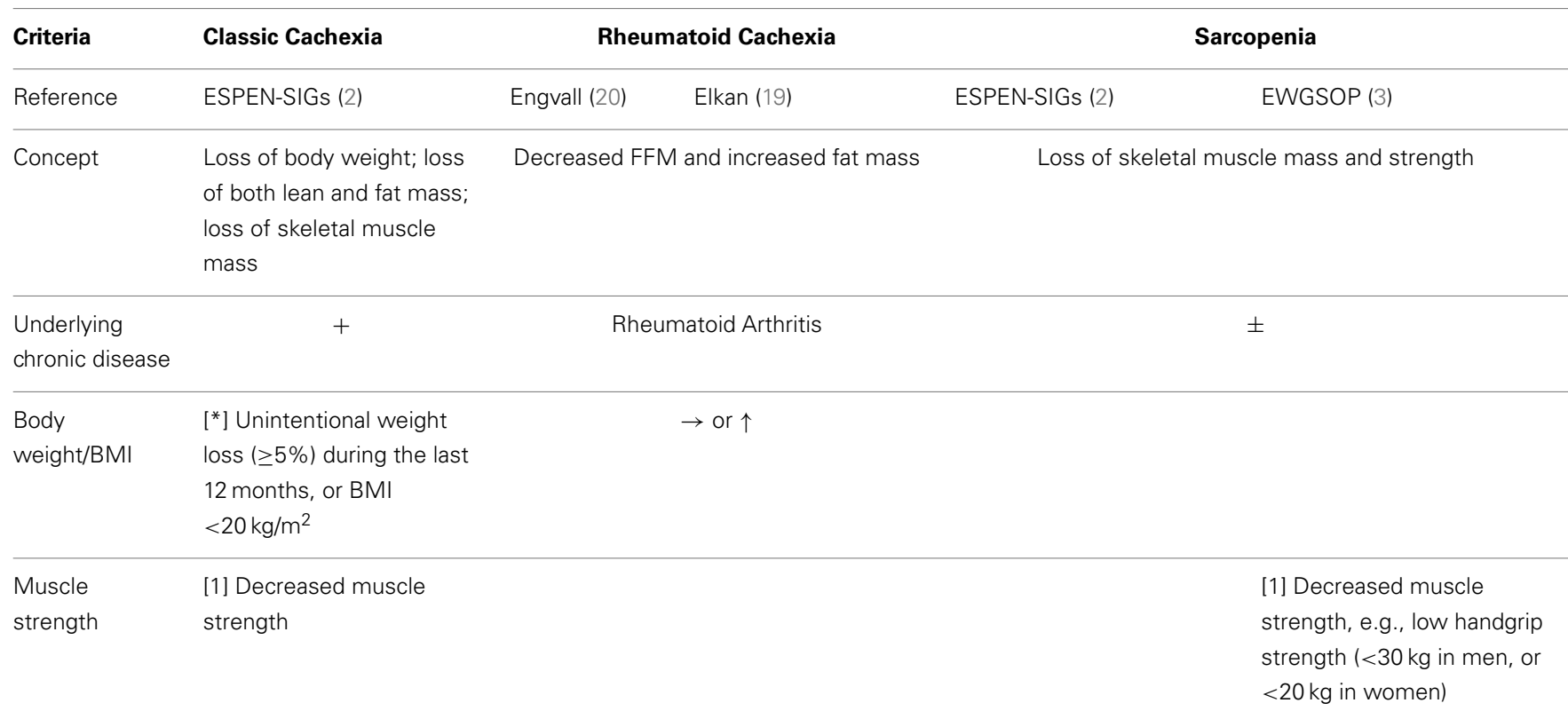

\begin{tabular}{|c|c|c|c|c|c|}
\hline Fatigue & [2] Fatigue & & & & \\
\hline $\begin{array}{l}\text { Body } \\
\text { composition }\end{array}$ & [4] Low FFM (lowest 10\%) & $\begin{array}{l}\text { FFMI }<10 \text { th } \\
\text { percentile and } \\
\text { FMI }>25 \text { th } \\
\text { percentile }\end{array}$ & $\begin{array}{l}\text { FFMI <25th } \\
\text { percentile and FMI } \\
>50 \text { th percentile }\end{array}$ & $\begin{array}{l}{\left[{ }^{*}\right] \text { Low muscle mass; e.g., }} \\
\geq 2 \text { SD below the mean in } \\
\text { young adults of the same } \\
\text { sex and ethnic background }\end{array}$ & $\begin{array}{l}{\left[{ }^{*}\right] \text { Low muscle mass; e.g., }} \\
\geq 2 \text { SD below the mean in } \\
\text { young adults }\end{array}$ \\
\hline $\begin{array}{l}\text { Role of } \\
\text { cytokines }\end{array}$ & $\begin{array}{l}\text { [5] Evidence of cytokine } \\
\text { excess: (1) CRP } \\
>0.5 \mathrm{mg} / \mathrm{dL} \text { or IL-6 }>4.0 \\
\mathrm{pg} / \mathrm{ml} \text {, (2) } \mathrm{Hb}<12 \mathrm{~g} / \mathrm{dl} \text {, (3) } \\
\text { Alb }<3.2 \mathrm{~g} / \mathrm{dL}\end{array}$ & \multicolumn{2}{|c|}{$\begin{array}{l}\text { Dominance of inflammatory cytokines } \\
\text { (in particular TNF } \alpha \text { and IL-6) due to } \\
\text { inflammatory arthritis }\end{array}$} & & \\
\hline $\begin{array}{l}\text { Diagnostic } \\
\text { criteria }\end{array}$ & $\begin{array}{l}\text { Defined as cachexia if [*] } \\
\text { plus } \geq 3 \text { among [1] to [5] } \\
\text { are fulfilled }\end{array}$ & \multicolumn{2}{|c|}{ No consensus on the cut-off values } & $\begin{array}{l}\text { Defined as sarcopenia if [*] } \\
\text { plus [1] or [2] are fulfilled }\end{array}$ & $\begin{array}{l}\text { Defined as sarcopenia if [*] } \\
\text { plus [1] or either of [2] are } \\
\text { fulfilled }\end{array}$ \\
\hline
\end{tabular}

$\left[{ }^{*}\right]$ indicates necessary condition for the diagnosis of "classic condition."

[1-5] indicates other conditions used for the diagnosis. (as described in "Diagnostic Criteria" in the Table).

Modified from Muscaritoli et al. (2). EWGSOP, European Working Group on Sarcopenia in Older People: FFM, fat-free mass; FFMI, fat-free mass index; CGA, Comprehensive Geriatric Assessment; SPPB, short physical performance battery, Hb, hemoglobin; Alb, albumin; SD, standard deviation.

immobility, and/or malnutrition. Although sarcopenia is generally an age-related condition, it can develop at a younger age, similar to other typically age-related conditions such as dementia and osteoporosis (3). The European Working Group on Sarcopenia in Older
People (EWGSOP) developed a clinical definition, and consensus diagnostic criteria for sarcopenia (Table 1). According to this definition, most cachectic patients are sarcopenic, but sarcopenic patients are not necessarily cachectic (3). 
In sarcopenia, the decreased muscle mass may be associated with normal, or even increased fat mass, a condition termed "sarcopenic obesity." It has been reported that fat infiltration into muscle would lower muscle quality (3).

\section{RHEUMATOID CACHEXIA}

Rheumatoid arthritis is an autoimmune disease that affects multiple synovial joints, and is associated with multiple extra-articular manifestations. Synovial fibroblasts and macrophages, activated by an unknown trigger, proliferate and produce a plethora of pro-inflammatory cytokines and catabolic proteases that would degrade bone and cartilage.

Due to the chronic inflammation, RA patients often exert abnormal metabolism, including insulin resistance $(4,5)$. Further, patients with refractory RA or in advanced stage of RA have been recognized to be at risk of cachexia. To this concern, for example, apparent BW loss ( $\geq 5 \%$ in past 12 months) was in $1.0 \%$, whereas anorexia was shown in 5.8 (when assessed with visual analog scale) to $10.7 \%$ (when assessed with the functional assessment of anorexia/cachexia therapy), in RA patients; overall, it has been estimated that patients with "classic" cachexia (Table 1) would be approximately $1.0 \%$ in RA patients (6). In addition, to support the inflammation-induced cachectic condition, an animal model of RA had decreased daily food intake (anorexia) and BW loss, accompanied with muscle wasting (7). Nevertheless, RA patients do not necessarily lose BW and often show normal range of BMI; thus may not fit into the diagnostic criteria of "cachexia" (as indicated in Table 1). Instead, a unique abnormal metabolic state, i.e., rheumatoid cachexia, has been proposed.

Specifically, in early studies, Roubenoff et al. documented decreased body cell mass (BCM) and increased resting energy expenditure (REE) in patients with RA, suggesting involvement of cytokine-driven hyper-metabolism $(8,9)$. The authors concluded that "cytokine production in RA is associated with altered energy metabolism and intake, despite a theoretically adequate diet," and defined the condition of reduced BCM without obvious fat loss as "rheumatoid cachexia" $(8,10)$. Thus, long-standing inflammation in RA leads to a state of hyper-metabolism resulting in muscle wasting (11).

A number of studies followed to assess the clinical implications of altered body composition in RA [Table S1 in Supplementary Material; earlier studies are summarized in a review by Summers et al. (12)]. Most reports documented that muscle mass in RA patients was decreased, whereas the fat mass remained normal, or was increased. REE was normal or increased, with some studies showing a correlation between REE and disease activity (11, $13,14)$. On the other hand, total energy expenditure (TEE) was reported to be lower than healthy controls (15), that is attributed to a reduced physical activity $(16,17)$.

Overall, the combined effect (i.e., loss of muscle mass and normal fat deposition) would keep BW within a normal range (18). This condition can be defined as rheumatoid cachexia, or rheumatoid cachectic obesity $(8,10,13)$, which is consistent with reports that $\mathrm{BMI}$ is not appropriate to detect rheumatoid cachexia $(19,21)$. In addition, the widely used mini nutritional assessment (MNA) was not a powerful tool for detection of rheumatoid cachexia $(19,21)$.
To date, there remain no consensus clinical criteria for the diagnosis of rheumatoid cachexia. Van Bokhorst-de van der Schueren et al. (6) assessed the feasibility of using the ESPEN SIG definition of cachexia in a sample of 103 RA patients, and concluded that the definition was inappropriate, since reductions in BW and appetite are not apparent in RA. Engvall et al. (20) and Elkan (22) defined rheumatoid cachexia using different criteria (Table 1), and estimated the frequency of rheumatoid cachexia as $38 \%$, or $18 \%$ of women and $21 \%$ of men, respectively. Effort is therefore needed to establish the diagnostic criteria for rheumatoid cachexia (18).

\section{PATHOGENESIS OF RHEUMATOID CACHEXIA}

A variety of factors are involved in the pathogenesis of classic cachexia, including suppression of the growth hormone $(\mathrm{GH})$ /insulin-like growth factor (IGF) system; testosterone deficiency; and an excess of myostatin and glucocorticoids (16). In rheumatoid cachexia, relative excess of pro-inflammatory cytokines is considered to be the central feature (9). Proinflammatory cytokines including TNF $\alpha$, IL-1 $\beta$, IL-6, and IFN- $\gamma$, the key players of synovitis and extra-articular manifestations, may activate the nuclear factor $\kappa \mathrm{B}$ and lead to an increase in muscle proteolysis via the ubiquitin-proteasome pathway (16). Overexpression of IL-1 $\beta$ would also induce anorexia and exacerbate muscle loss (9). Further, use of glucocorticoid as a pharmacological treatment against symptoms of RA might aggravate the rheumatoid cachexia. More specifically, glucocorticoids have been shown to induce muscle atrophy (steroid myopathy) through activation of the transcription factor FOXO or repression of mTOR signaling, leading to protein catabolism (23).

The GH-IGF axis may also be an important contributor, although controversy exists (24). In an animal model of chronic inflammatory arthritis, Ibanez de Caceres et al. reported a decrease in BW and reduced levels of circulating IGF-1; administration of recombinant $\mathrm{GH}$ was associated with increased BW gain without an increase in food intake, and increased levels of IGF-1 (25). On the other hand, in the model, arthritis was also associated with increased expression of the cyclooxygenase (COX)2 gene; and administration of non-steroidal anti-inflammatory drugs (NSAIDS) reversed the COX's inhibitory effect of arthritis on BW, increased liver IGF-1 levels, and enhanced the expression of ubiquitin-ligating enzymes. The authors suggested that COX2 expression was responsible for the arthritis-induced cachexia, through modification of the GH-IGF axis and the ubiquitinproteasome pathways (25). The use of recombinant GH in cachectic humans has been also approved for use in patients with AIDS (26); however, its efficacy in patients with RA is unclear.

\section{THERAPEUTIC STRATEGY AGAINST RHEUMATOID CACHEXIA}

The consequences of rheumatoid cachexia go beyond muscle wasting and fat deposition; while any impact on cardiovascular risk remains controversial (18), it is suggested that rheumatoid cachexia exacerbates RA-associated disability and morbidity (17, 27 ), probably leading to sarcopenia. The muscle volume of RA patients is reported to correlate with RA activity, not with dietary intake $(14,17)$. Further, even in RA patients with a high dietary 
intake of saturated fat, there was no correlation between fatty acid intake and rheumatoid cachexia (22). The most important strategy against metabolic abnormalities in RA may be the appropriate suppression of disease activity, for example, using anti-cytokine therapy and physical exercise (28).

\section{DISEASE-MODIFYING ANTI-RHEUMATIC DRUGS}

Rheumatoid arthritis patients typically start anti-rheumatic therapy using conventional disease-modifying anti-rheumatic drugs (DMARDs), which may include methotrexate (MTX) as an anchor drug, and sulfasalazine (SSZ). These agents are effective in the suppression of disease activity, particularly when used in combination. The use of DMARDs in early RA is also reported to improve insulin resistance and dyslipidemia $(5,29,30)$; this is likely due to their disease-modifying effects, rather than a direct effect on metabolism, since neither MTX nor azathioprine, when used alongside NSAIDs, was shown to affect energy metabolism in RA patients (9). Indeed, insulin resistance in RA patients was shown to be higher than that observed in patients with systemic lupus erythematosus, and was correlated with serum levels of IL-6, TNF $\alpha$, and C-reactive protein (CRP) $(30,31)$. Perhaps surprisingly, use of predonisolone in RA patients had no correlation with BCM (Table S1 in Supplementary Material) (9).

\section{ANTI-CYTOKINE THERAPIES}

Over the last decade, data have accumulated regarding the longterm use of anti-TNF agents in RA patients. While solid evidence exists for their anti-arthritic efficacy, few reports indicate whether anti-TNF agents could improve rheumatoid cachexia.

Marcora et al. (32) analyzed change in body composition in 26 RA patients after 24 weeks treatment using etanercept (ETN) or MTX, and failed to find significant benefit of ETN compared with MTX. However, in a subgroup analysis of patients who gained BW during treatment, the ETN-treated patients gained a greater proportion of FFM (in the composition of the BW gained) than the MTX-treated group. Similarly, Elkan et al. (21) found no correlation between use of anti-TNF agents and body composition.

After a longer period of observation (1 year), Chen et al. (33) found that twice weekly administration of ETN was associated with increased BW, and increased serum levels of glucosedependent insulinotropic polypeptide (GIP), leptin, and ghrelin compared with treatment with DMARDs. Further, a recent prospective study (34) involving a 2-year period of TNF $\alpha$ inhibition, demonstrated an increase in BW, BMI, total fat mass, and fat in the android (truncal) region; visceral fat also increased, without any change in serum leptin and adiponectin levels. The authors concluded that long-term TNF inhibition was associated with increased fat mass, with a shift to the android-visceral region, raising questions regarding the influence of TNF inhibition on cardiovascular risk. This association is surprising, given that anti-TNF therapy is reported to improve insulin resistance in RA patients (30, 35-38).

IL-6 is another important pathogenic cytokine in both classic and rheumatoid cachexia. Serum IL-6 levels in RA patients are higher than those of healthy individuals, and are reported to correlate with a high $\operatorname{REE}(11,14)$. However, it remains unclear whether
IL-6 levels correlate with muscle mass and/or visceral fat mass in RA (11). Further studies are needed to clarify the involvement of IL-6 in muscle degradation, and the potential effect of the antirheumatic agent tocilizmab, a widely used monoclonal antibody against the IL-6 receptor, in rheumatoid cachexia.

\section{RESISTANCE TRAINING AND ENDURANCE TRAINING}

Summers et al. suggested that alongside anti-cytokine therapy, adjunctive anabolic therapy, such as high-intensity progressive resistance training (PRT) or nitrogen supplementation would be necessary to treat rheumatoid cachexia (12).

Accumulating evidence supports the significant clinical benefit of resistance training in patients with RA [reviewed in Ref. (28)]. Regular training not only increased muscle strength but also improved disease activity, pain, Health Assessment Questionnaire (HAQ) scores, and walking speed in RA patients $(28,39-45)$. For example, Marcola (44) and Lemmey et al. (45) reported that PRT for a period of 12 and 24 weeks, respectively, increased muscle mass while reducing fat mass. Lemmey et al. also reported improvements in physical performance, while levels of muscle IGF-1 and IGF-binding protein (IGFBP)-3 in muscle increased (45).

Besides the resistance training, endurance training (ET) is also important to improve insulin sensitivity and body composition (46). In a report by Mikkelsen et al. (47), it was revealed that life-long endurance exercise was associated with lower levels of circulating CRP and IL-6 levels, and also with a greater muscle area compared to untrained controls, indicating potential antiinflammatory effect of ET. In fact, the combination of resistance training and ET has been demonstrated to increase lean body mass and to decrease body fat in RA patients $(48,49)$. These findings suggest the therapeutic potential of these physical therapies in RA and other chronic inflammatory conditions.

\section{OTHER APPROACHES}

$\alpha$-Melanocyte-stimulating hormone $(\alpha-\mathrm{MSH})$ is a proopiomelanocortin (POMC)-derived neuropeptide that exerts anorexigenic and anti-inflammatory properties (50). Recently, GómezSanMiguel et al. (7) reported that systemic administration of $\alpha$-MSH to arthritis model mice resulted in improved food intake and higher BW gain with decreased arthritis signs. The authors found that increase in hypothalamic expressions of COX-2, IL$1 \beta$, POMC, and Agouti-related protein (a stimulator of appetite) mRNA were prevented by $\alpha-\mathrm{MSH}$ administration in the arthritic mice. $\alpha$-MSH treatment also decreased expressions of E3 ubiquitin ligases, which are markers of muscular atrophy. Thus peripheral $\alpha$-MSH treatment is suggested to be an anti-cachectic strategy in arthritis.

Other approaches such as anabolic steroids or recombinant human GH have been proposed, however, there is no evidence to show their safety and efficacy (28).

\section{CONCLUDING REMARIKS}

Recent progress in anti-rheumatic therapies has made "classic" cachexia less frequent among RA patients. Nevertheless, a different form of abnormal metabolism, "rheumatoid cachexia," has emerged, that may promote comorbid risks and deterioration in physical activity in RA patients (Figure 1). 


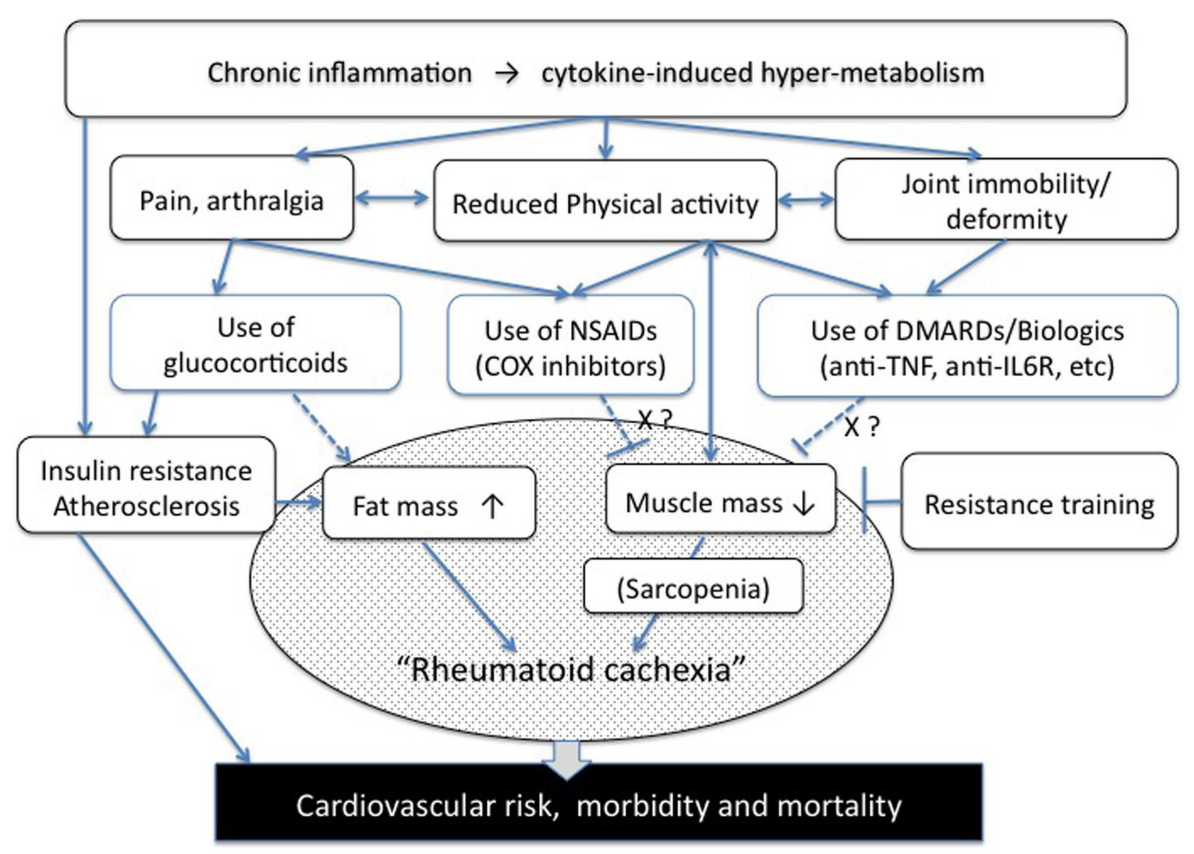

FIGURE 1 | Pathogenesis of rheumatoid cachexia (a hypothesis). NSAIDs, non-steroidal anti-inflammatory drugs, COX, cyclooxygenase; DMARDs, disease-modifying anti-rheumatic drugs.

To overcome the muscle loss and fat deposit in RA, it will be essential to first establish a consensus regarding definition of this disorder. Possible overlap with sarcopenia should be also noted. Further, tight control of disease activity, along with physical exercise and appropriate nutritional management, should be recommended to improve energy expenditure and reduce insulin resistance in RA patients.

\section{ACKNOWLEDGMENTS}

The author thanks Ms. Ami Hirota for her excellent secretarial support.

\section{SUPPLEMENTARY MATERIAL}

The Supplementary Material for this article can be found online at http://www.frontiersin.org/Journal/10.3389/fnut.2014. 00020/abstract

Table S1 | Reported changes of indices of body composition in RA patients. References: (6, 8, 10, 15, 16, 18, 20, 24, 43-50). Disease Activity Score-28 (51) of the tested patients were 2.6-6.39 and the Health Assessment Questionnaire (52) score was around 0.22-1.95. BCM, body cell mass; FFM, fat-free mass; LBM, lean body mass; AMA, arm muscle area, TEE: total energy expenditure, REE: resting energy expenditure. Biologics: TNF, TNF $\alpha$ inhibitors; IL-6, IL-6 receptor antagonist; CD20, CD20 inhibitor; $\uparrow$, increased; $\downarrow$, decreased; $\rightarrow$, no change compared with the control group, respectively. ${ }^{*}$ Values shown are at the patient's first visit (baseline).

\section{REFERENCES}

1. Evans WJ, Morley JE, Argiles J, Bales C, Baracos V, Guttridge D, et al. Cachexia: a new definition. Clin Nutr (2008) 27:793-9. doi:10.1016/j.clnu.2008. 06.013

2. Muscaritoli M, Anker SD, Argiles J, Aversa Z, Bauer JM, Biolo G, et al. Consensus definition of sarcopenia, cachexia and pre-cachexia: joint document elaborated by Special Interest Groups (SIG) "cachexia-anorexia in chronic wasting diseases" and "nutrition in geriatrics". Clin Nutr (2010) 29:154-9. doi:10.1016/j.clnu.2009.12.004

3. Cruz-Jentoft AJ, Baeyens JP, Bauer JM, Boirie Y, Cederholm T, Landi F, et al. Sarcopenia: European consensus on definition and diagnosis: report of the European Working Group on Sarcopenia in Older People. Age Ageing (2010) 39:412-23. doi:10.1093/ageing/afq034

4. Svenson KL, Pollare T, Lithell H, Hallgren R. Impaired glucose handling in active rheumatoid arthritis: relationship to peripheral insulin resistance. Metabolism (1988) 37:125-30. doi:10.1016/S0026-0495(98)90005-1

5. Chung CP, Oeser A, Solus JF, Gebretsadik T, Shintani A, Avalos I, et al. Inflammation-associated insulin resistance: differential effects in rheumatoid arthritis and systemic lupus erythematosus define potential mechanisms. Arthritis Rheum (2008) 58:2105-12. doi:10.1002/art.23600

6. van Bokhorst-de van der Schueren MA, Konijn NP, Bultink IE, Lems WF, Earthman CP. Relevance of the new pre-cachexia and cachexia definitions for patients with rheumatoid arthritis. Clin Nutr (2012) 31:1008-10. doi:10.1016/j.clnu. 2012.05.012

7. Gómez-SanMiguel AB, Martin AI, Nieto-Bona MP, Fernandez-Galaz C, LopezMenduina M, Villanua MA, et al. Systemic alpha-melanocyte-stimulating hormone administration decreases arthritis-induced anorexia and muscle wasting. Am J Physiol Regul Integr Comp Physiol (2013) 304:R877-86. doi:10.1152/ ajpregu.00447.2012

8. Roubenoff R, Roubenoff RA, Ward LM, Holland SM, Hellmann DB. Rheumatoid cachexia: depletion of lean body mass in rheumatoid arthritis. Possible association with tumor necrosis factor. J Rheumatol (1992) 19:1505-10.

9. Roubenoff R, Roubenoff RA, Cannon JG, Kehayias JJ, Zhuang H, DawsonHughes B, et al. Rheumatoid cachexia: cytokine-driven hypermetabolism accompanying reduced body cell mass in chronic inflammation. J Clin Invest (1994) 93:2379-86. doi:10.1172/JCI117244

10. Walsmith J, Roubenoff R. Cachexia in rheumatoid arthritis. Int J Cardiol (2002) 85:89-99. doi:10.1016/S0167-5273(02)00237-1

11. Arshad A, Rashid R, Benjamin K. The effect of disease activity on fat-free mass and resting energy expenditure in patients with rheumatoid arthritis versus noninflammatory arthropathies/soft tissue rheumatism. Mod Rheumatol (2007) 17:470-5. doi:10.3109/s10165-007-0628-1 
12. Summers G, Deighton C, Rennie M, Booth A. Rheumatoid cachexia: a clinical perspective. Rheumatology (Oxford) (2008) 47:1124-31. doi:10.1093/ rheumatology/ken146

13. Roubenoff R, Walsmith J, Lundgren N, Snydman L, Dolnikowski GJ, Roberts S. Low physical activity reduces total energy expenditure in women with rheumatoid arthritis: implications for dietary intake recommendations. Am J Clin Nutr (2002) 76:774-9.

14. Binymin K, Herrick A, Carlson G, Hopkins S. The effect of disease activity on body composition and resting energy expenditure in patients with rheumatoid arthritis. J Inflamm Res (2011) 4:61-6. doi:10.2147/JIR.S16508

15. Henchoz Y, Bastardot F, Guessous I, Theler JM, Dudler J, Vollenweider P, et al. Physical activity and energy expenditure in rheumatoid arthritis patients and matched controls. Rheumatology (Oxford) (2012) 51:1500-7. doi:10.1093/ rheumatology/kes067

16. Morley JE, Thomas DR, Wilson MM. Cachexia: pathophysiology and clinical relevance. Am J Clin Nutr (2006) 83:735-43.

17. Rall LC, Roubenoff R. Rheumatoid cachexia: metabolic abnormalities, mechanisms and interventions. Rheumatology (Oxford) (2004) 43:1219-23. doi:10. 1093/rheumatology/keh321

18. Summers GD, Metsios GS, Stavropoulos-Kalinoglou A, Kitas GD. Rheumatoid cachexia and cardiovascular disease. Nat Rev Rheumatol (2010) 6:445-51. doi:10.1038/nrrheum.2010.105

19. Elkan A, Engvall I, Tengstrand B, Cederholm T, Hafstrom I. Malnutrition in women with rheumatoid arthritis is not revealed by clinical anthropometrical measurements or nutritional evaluation tools. Eur J Clin Nutr (2008) 62:1239-47. doi:10.1038/sj.ejcn.1602845

20. Engvall I, Elkan A, Tengstrand B, Cederholm T, Brismar K, Hafstrom I. Cachexia in rheumatoid arthritis is associated with inflammatory activity, physical disability, and low bioavailable insulin-like growth factor. Scand J Rheumatol (2008) 37:1-8. doi:10.1080/03009740802055984

21. Elkan AC, Engvall IL, Cederholm T, Hafstrom I. Rheumatoid cachexia, central obesity and malnutrition in patients with low-active rheumatoid arthritis: feasibility of anthropometry, Mini Nutritional Assessment and body composition techniques. Eur J Nutr (2009) 48:315-22. doi:10.1007/s00394-0090017-y

22. Elkan AC, Hakansson N, Frostegard J, Cederholm T, Hafstrom I. Rheumatoid cachexia is associated with dyslipidemia and low levels of atheroprotective natural antibodies against phosphorylcholine but not with dietary fat in patients with rheumatoid arthritis: a cross-sectional study. Arthritis Res Ther (2009) 11:R37. doi:10.1186/ar2643

23. Schakman O, Gilson H, Thissen JP. Mechanisms of glucocorticoid-induced myopathy. J Endocrinol (2008) 197:1-10. doi:10.1677/JOE-07-0606

24. Rall LC, Walsmith JM, Snydman L, Reichlin S, Veldhuis JD, Kehayias JJ, et al. Cachexia in rheumatoid arthritis is not explained by decreased growth hormone secretion. Arthritis Rheum (2002) 46:2574-7. doi:10.1002/art.10714

25. Ibanez De Caceres I, Villanua MA, Soto L, Martin AI, Lopez-Calderon A. IGF-I and IGF-I-binding proteins in rats with adjuvant-induced arthritis given recombinant human growth hormone. J Endocrinol (2000) 165:537-44. doi:10.1677/joe.0.1650537

26. Gullett NP, Hebbar G, Ziegler TR. Update on clinical trials of growth factors and anabolic steroids in cachexia and wasting. Am J Clin Nutr (2010) 91:1143S-7S. doi:10.3945/ajcn.2010.28608E

27. Walsmith J, Abad L, Kehayias J, Roubenoff R. Tumor necrosis factor-alpha production is associated with less body cell mass in women with rheumatoid arthritis. J Rheumatol (2004) 31:23-9.

28. Lemmey A. Resistance training for patients with rheumatoid arthritis: effects on disability, rheumatoid cachexia, and osteoporosis; and recommendations for prescription. In: Lemmey DA, editor. Rheumatoid Arthritis - Treatment. Rijeka, Croatia: InTech (2012). p. 287-310.

29. Dessein PH, Joffe BI, Stanwix AE. Effects of disease modifying agents and dietary intervention on insulin resistance and dyslipidemia in inflammatory arthritis: a pilot study. Arthritis Res (2002) 4:R12. doi:10.1186/ar428

30. Ferraz-Amaro I, Gonzalez-Juanatey C, Lopez-Mejias R, Riancho-Zarrabeitia L, Gonzalez-Gay MA. Metabolic syndrome in rheumatoid arthritis. Mediators Inflamm (2013) 2013:710928. doi:10.1155/2013/710928

31. Rodriguez LA, Tolosa LB, Ruigomez A, Johansson S, Wallander MA. Rheumatoid arthritis in UK primary care: incidence and prior morbidity. Scand J Rheumatol (2009) 38:173-7. doi:10.1080/03009740802448825
32. Marcora SM, Chester KR, Mittal G, Lemmey AB, Maddison PJ. Randomized phase 2 trial of anti-tumor necrosis factor therapy for cachexia in patients with early rheumatoid arthritis. Am J Clin Nutr (2006) 84:1463-72.

33. Chen CY, Tsai CY, Lee PC, Lee SD. Long-term etanercept therapy favors weight gain and ameliorates cachexia in rheumatoid arthritis patients: roles of gut hormones and leptin. Curr Pharm Des (2013) 19:1956-64. doi:10.2174/ 1381612811319100014

34. Toussirot E, Mourot L, Dehecq B, Wendling D, Grandclement E, Dumoulin G. TNFalpha blockade for inflammatory rheumatic diseases is associated with a significant gain in android fat mass and has varying effects on adipokines: a 2year prospective study. Eur J Nutr (2014) 53:951-61. doi:10.1007/s00394-0130599-2

35. Kiortsis DN, Mavridis AK, Vasakos S, Nikas SN, Drosos AA. Effects of infliximab treatment on insulin resistance in patients with rheumatoid arthritis and ankylosing spondylitis. Ann Rheum Dis (2005) 64:765-6. doi:10.1136/ard.2004. 026534

36. Sarzi-Puttini P, Atzeni F, Scholmerich J, Cutolo M, Straub RH. Anti-TNF antibody treatment improves glucocorticoid induced insulin-like growth factor 1 (IGF1) resistance without influencing myoglobin and IGF1 binding proteins 1 and 3. Ann Rheum Dis (2006) 65:301-5. doi:10.1136/ard.2005.040816

37. Gonzalez-Gay MA, Gonzalez-Juanatey C, Vazquez-Rodriguez TR, MirandaFilloy JA, Llorca J. Insulin resistance in rheumatoid arthritis: the impact of the anti-TNF-alpha therapy. Ann N Y Acad Sci (2010) 1193:153-9. doi:10.1111/j. 1749-6632.2009.05287.x

38. Stagakis I, Bertsias G, Karvounaris S, Kavousanaki M, Virla D, Raptopoulou A, et al. Anti-tumor necrosis factor therapy improves insulin resistance, beta cell function and insulin signaling in active rheumatoid arthritis patients with high insulin resistance. Arthritis Res Ther (2012) 14:R141. doi:10.1186/ar3874

39. Hakkinen A, Sokka T, Kotaniemi A, Hannonen P. A randomized two-year study of the effects of dynamic strength training on muscle strength, disease activity, functional capacity, and bone mineral density in early rheumatoid arthritis. Arthritis Rheum (2001) 44:515-22. doi:10.1002/1529-0131(200103)44:3<515: :AID-ANR98 > 3.0.CO;2-5

40. Hurkmans E, van der Giesen FJ, Vliet Vlieland TP, Schoones J, Van den Ende EC. Dynamic exercise programs (aerobic capacity and/or muscle strength training) in patients with rheumatoid arthritis. Cochrane Database Syst Rev (2009):CD006853. doi:10.1002/14651858.CD006853.pub2

41. Sharif S, Thomas JM, Donley DA, Gilleland DL, Bonner DE, McCrory JL, et al. Resistance exercise reduces skeletal muscle cachexia and improves muscle function in rheumatoid arthritis. Case Report Med (2011) 2011:205691. doi:10.1155/2011/205691

42. Baillet A, Vaillant M, Guinot M, Juvin R, Gaudin P. Efficacy of resistance exercises in rheumatoid arthritis: meta-analysis of randomized controlled trials. Rheumatology (Oxford) (2012) 51:519-27. doi:10.1093/rheumatology/ ker330

43. Marcora S, Lemmey A, Maddison P. Dietary treatment of rheumatoid cachexia with beta-hydroxy-beta-methylbutyrate, glutamine and arginine: a randomised controlled trial. Clin Nutr (2005) 24:442-54. doi:10.1016/j.clnu. 2005.01.006

44. Marcora SM, Lemmey AB, Maddison PJ. Can progressive resistance training reverse cachexia in patients with rheumatoid arthritis? Results of a pilot study. $J$ Rheumatol (2005) 32:1031-9.

45. Lemmey AB, Marcora SM, Chester K, Wilson S, Casanova F, Maddison PJ. Effects of high-intensity resistance training in patients with rheumatoid arthritis: a randomized controlled trial. Arthritis Rheum (2009) 61:1726-34. doi:10.1002/art.24891

46. Dumortier M, Brandou F, Perez-Martin A, Fedou C, Mercier J, Brun JF. Low intensity endurance exercise targeted for lipid oxidation improves body composition and insulin sensitivity in patients with the metabolic syndrome. Diabetes Metab (2003) 29:509-18. doi:10.1016/S1262-3636(07)70065-4

47. Mikkelsen UR, Couppe C, Karlsen A, Grosset JF, Schjerling P, Mackey AL, et al. Life-long endurance exercise in humans: circulating levels of inflammatory markers and leg muscle size. Mech Ageing Dev (2013) 134:531-40. doi:10.1016/j.mad.2013.11.004

48. Hakkinen A, Pakarinen A, Hannonen P, Kautiainen H, Nyman K, Kraemer WJ, et al. Effects of prolonged combined strength and endurance training on physical fitness, body composition and serum hormones in women with rheumatoid arthritis and in healthy controls. Clin Exp Rheumatol (2005) 23:505-12. 
49. Strasser B, Leeb G, Strehblow C, Schobersberger W, Haber P, Cauza E. The effects of strength and endurance training in patients with rheumatoid arthritis. Clin Rheumatol (2011) 30:623-32. doi:10.1007/s10067010-1584-2

50. Luger TA, Brzoska T. alpha-MSH related peptides: a new class of antiinflammatory and immunomodulating drugs. Ann Rheum Dis (2007) 66(Suppl 3):iii52-5.

51. Prevoo ML, van 't Hof MA, Kuper HH, van Leeuwen MA, van de Putte LB, van Riel PL. Modified disease activity scores that include twenty-eight-joint counts. Development and validation in a prospective longitudinal study of patients with rheumatoid arthritis. Arthritis Rheum (1995) 38:44-8. doi:10.1002/art. 1780380107

52. Hochberg MC, Chang RW, Dwosh I, Lindsey S, Pincus T, Wolfe F. The American College of Rheumatology 1991 revised criteria for the classification of global functional status in rheumatoid arthritis. Arthritis Rheum (1992) 35:498-502. doi:10.1002/art.1780350502
Conflict of Interest Statement: The author declares that the research was conducted in the absence of any commercial or financial relationships that could be construed as a potential conflict of interest.

Received: 22 September 2014; accepted: 03 November 2014; published online: 24 November 2014.

Citation: Masuko K (2014) Rheumatoid cachexia revisited: a metabolic co-morbidity in rheumatoid arthritis. Front. Nutr. 1:20. doi: 10.3389/fnut.2014.00020

This article was submitted to Clinical Nutrition, a section of the journal Frontiers in Nutrition.

Copyright (C) 2014 Masuko. This is an open-access article distributed under the terms of the Creative Commons Attribution License (CC BY). The use, distribution or reproduction in other forums is permitted, provided the original author(s) or licensor are credited and that the original publication in this journal is cited, in accordance with accepted academic practice. No use, distribution or reproduction is permitted which does not comply with these terms. 